\title{
Advances in the Use of Caenorhabditis Choose in the Nutritional Study of Obesity
}

\section{Taufner GH ${ }^{*}$, Costa DS, Zanardo TEC and Destefani AC}

The Federal University of Espírito Santo (UFES), Av. Marechal Campus, 1468 - Maruípe, Vitória/ES-Brazil, CEP 29043-900

*Corresponding author: Gabriel Henrique Taufner, Master student in Biotechnology from the Federal University of Espírito Santo (UFES), Av. Marechal Campus, 1468 - Maruípe, Vitória/ES-Brazil, CEP 29043-900, Tel: +5527998909696; E-mail: Gabrielhtaufner@hotmail.com

Received date: March 16, 2017; Accepted date: March 31, 2017; Published date: April 07, 2017

Copyright: ( 2017 Taufner $\mathrm{GH}$, et al. This is an open-access article distributed under the terms of the Creative Commons Attribution License, which permits unrestricted use, distribution, and reproduction in any medium, provided the original author and source are credited.

\begin{abstract}
Obesity is characterized as a health problem of high prevalence worldwide, and to date, about two thirds of the US population is affected, generating a high financial cost for health management systems. Traditionally, the model for the study of obesity has been rodents, mainly rats and mice, and although the obesity field has progressed a lot, there has been a clear need for a cheaper and more efficient model. C. elegans is a small worm with a life expectancy of about 21 days that possesses rapid growth and feeds on non-pathogenic strains of Escherichia coli. This small nematode has about 60 to 80 percent of its genes related to human diseases, and it is now known to the scientific community that manipulating its genome can provide valuable information to define the pathophysiological aspects of obesity. C. elegans has been successfully reported as an animal model in research related to nutritional physiology, in addition to the characterization of several metabolic pathways, storage mechanisms and lipid release. In recent years, due to the advances of $C$. elegans in the physiological characterization of lipid metabolism, it is now possible with its use as an animal model to offer the possibility of in vivo identification of compounds that modulate fat storage.
\end{abstract}

Keywords: Animal model; Caenorhabditis elegans, Metabolic; Obesity

\section{Introduction}

Obesity is characterized by being a condition of high prevalence worldwide, to date, two thirds of the US population is affected [1-4]. It is associated with insulin resistance and an increased risk of developing diabetes and cardiovascular disease 4-7. In general, obesity, diabetes and cardiovascular disease are relatively expensive for health systems, so finding a solution to the recent obesity epidemic is gaining increasing importance $[8,9]$.

Traditionally, the model for the study of obesity has been rodents, mainly rats and mice, and although the field of obesity has progressed a lot with these animals, advancing in the characterization of metabolic pathways and functional analysis of new therapeutic approaches.

Over time, there has been a need for an easy to obtain model with reduced maintenance costs, a short, efficient and functionally similar life cycle for mammals, since the use of rodents takes time and cost as well as a large bureaucracy ethics committees $[1,10]$.

C. elegans is a small worm with a life expectancy of about 21 days that has rapid growth and feeds on non-pathogenic strains of Escherichia coli [11-14]. It's a little worm from all over the world. As newly hatched larvae are 0.25 millimeters in length and adults 1 millimeters in length (Figure 1) [11,14].

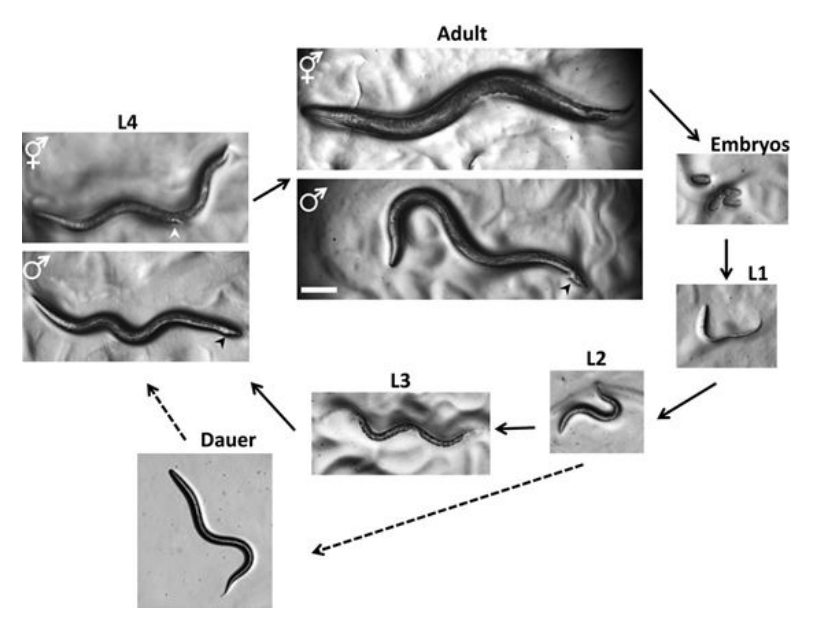

Figure 1: Life Cycle of $C$. elegans. Animals grow in size over the four larval stages, but the sexes are not easily identified for the L4 stage. In stage L4, hermaphrodites have a conical tail and a developing vulva (white arrowhead) can be seen as a clear half-circle in the center of the ventral side. Males have a longer tail (black arrowhead). In adults, the two sexes can be distinguished by a longer circumference and a tapering tail of the hermaphrodite and by the finer circumference and by the fan-shaped tail (black arrowhead) of the male. Oocytes may be fertilized by sperm from the hermaphrodite or sperm obtained from males through mating. Dauer larvae (longer lasting phase) are narrower than all other larval stages. Photographs were obtained on Petri dishes. Bar 0.1 $\mathrm{mm}[11]$. 
Its small size allows the animals to be observed with the dissecting microscopes, which have systems up to a magnification of $100 \mathrm{X}$, or composite microscopes, which allow a magnification of up to $1000 \mathrm{X}$. The dissecting microscope is used to observe the signals on Petri dishes (Figure 2A and 2B) as they move, eat, develop, mate, and lay eggs (for the films that show these features, see http://labs.bio.unc.edu/ goldstein/movies.html). A composite or confocal microscope allows much finer resolution observation (Figure 2C), allowing researchers to perform experiments that address issues related to cell development and a single cell recovery function. As $C$. elegans is transparent, as individual cells and the subcellular details are easily visualized using a Nomarski optic (differential interference contrast, DIC) (Figure 2C) The enhanced detail can be discerned using fluorescers to label proteins or subcellular compartments (Figure 2D). Fluorescent proteins can also be used to study developmental processes, to investigate mutants that affect development and function of cells, to isolate cells and to characterize interactions of proteins in vivo [15].
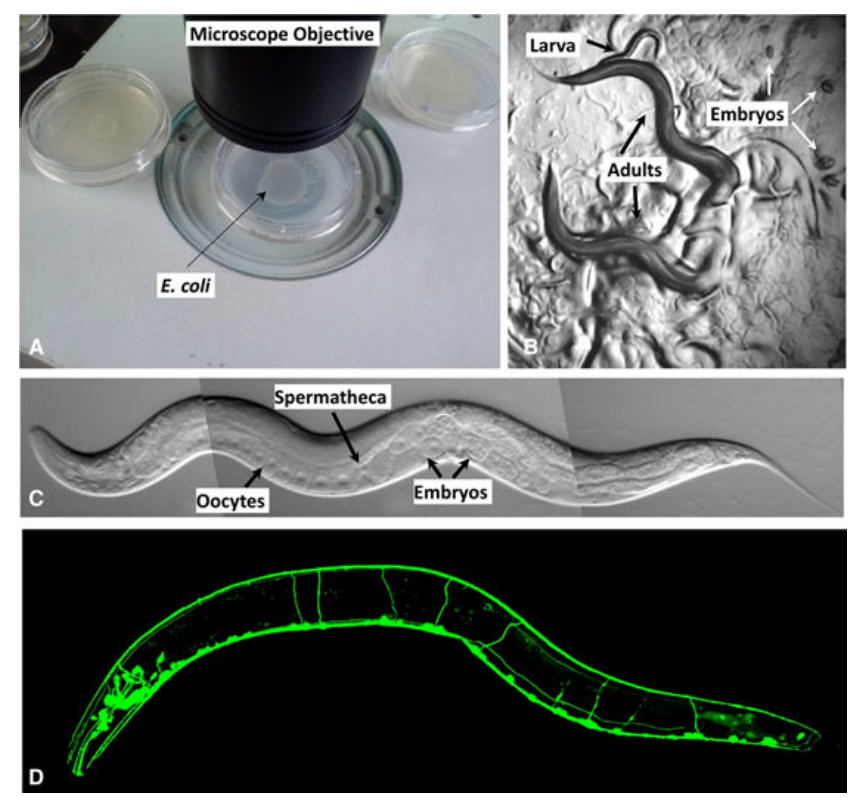

Figure 2: Observing C. elegans. (A) Petri dishes seated at the base of a dissecting stereomicroscope. Bacterial growth is visible on the patio surface without internal plaques, but $C$. elegans are too small to be seen in this way. (B) C. elegans seen through the dissecting microscope. The two adults are moving in this view. As tracks on the plate indicate where the animals have traversed the bacterial culture. (C) An adult airtight model is seen in a compound microscope. In all images, the anterior plane is to the left and the ventral plane is in the background. C. elegans moves from his left or right side; this image is the front surface for the reader on the left side. As animals are transparent, one can see, from left to right on the ventral side, the development of oocytes in the gonads (rectangular cells with a circular and light nucleus in the interior) followed by spermathecae (where oocytes are fertilized) and Multiple embryos: the uterus. (D) Fluorescent image showing the GFP-labeled nervous system (green fluorescent protein) [11].

This small nematode has about 60 to $80 \%$ of its genes related to human diseases $[1,11,16-19]$, and it is now known by the scientific community that manipulating it can provide valuable information to define the pathophysiological aspects of obesity [18].

The high prevalence of obesity and its related disorders highlight the need to understand the components and pathways that regulate lipid metabolism, since the energy balance is maintained by a complex network of regulation $[20,21]$. The use of a rich genetic model like $C$. elegans can complement studies on a mammalian physiology, offering new opportunities to identify genes and to dissect circuits responsible for the control of lipid metabolism [22,23]. Many of the components that are central to controlling human metabolism are preserved in the worm (Tabel 1) [22].

\begin{tabular}{|l|}
\hline Mammals and Caenorhabditis Elegans \\
\hline Nuclear hormone receptors \\
Transcriptional Regulators SREBP (Sterolytic Response Element Binding \\
Protein) \\
AMPK-activated kinase \\
Kinase TOR
\end{tabular}

Table 1: Central metabolic regulation pathways common among mammals and C. elegans.

Although the study of lipid metabolism in C. elegans is still relatively young, some progress has already been made to identify the genetic pathways that regulate fat storage using dietary compounds whose performance on obesity is already known. This animal model is very promising to help unravel the complicated path of genes that maintain an adequate energy balance. Considering the importance of the discovery of the pathways of these pathways of lipid metabolism, this article intends to carry out a bibliographical review on the use of Caenorhabditis elegans as animal model in the study of obesity.

\section{Elegans in the Assessment of Lipid Metabolism}

The mammals have as energetic source glucose and lipids. Lipids are important and present also in structural and physical processes, as well as being important in paper and in the normal functioning of membranes and in biosynthesis of hormones. Similar to mammals, $C$. elegans contains a large amount of saturated, monounsaturated and polyunsaturated fatty acids (PUFAs) including arachidonic acid and eicosapentaenoic acid [24,25]. Many metabolic pathways involved with the transport cycle and fat metabolism are highly conserved between C. elegans and mammals (Table 2) [22,26-31].

Despite the similarity of various metabolic pathways, the regulation of fat of $C$. elegans differs from mammals in some respects. Unlike mammals that store droplet-like lipids in adipocytes and hepatocytes $[20,30,32]$, in nematodes there are no fat cells derived from mesoderm dedicated specifically to fat storage. These animals store fat primarily in their intestinal and hypodermic epidermal cells, and since these worms are transparent, such reserves can be seen directly in intact animals (Figure 3) [1,33-36]. C. elegans also lacks certain key fat regulation mechanisms of mammals, for example, a leptin, which is a sign of nuclear adiposity derived from adipose cells in mammals. C. elegans are auxotrophic cholesterol, and they should get it through their diet. Since very small dietary amounts of cholesterol are sufficient for the viability of $C$. elegans, it is thought that cholesterol is not a necessary component of $C$. elegans cell membranes, but rather is required only for sterol-based signaling [37]. In addition, unlike mammals, $C$. elegans are not dependent on the supply of essential fatty acids (C18: $2 \mathrm{n} 6$ and $\mathrm{C} 18: 3 \mathrm{n} 3$ ), as they have the set of desaturases and elongases 
Citation: Taufner GH, Costa DS, Zanardo TEC, Destefani AC (2017) Advances in the Use of Caenorhabditis Choose in the Nutritional Study of Obesity. J Diabetes Metab 8: 735. doi:10.4172/2155-6156.1000735

Page 3 of 5

required for the synthesis of these lipids [24]. Despite the observed differences, a deep evolutionary conservation of the main metabolic pathways and their regulators suggest that, since analyzes of the lipid storage pathways in C. elegans should be widely informative.

\begin{tabular}{|l|l|}
\hline \multicolumn{2}{|l|}{ Mammals e Caenorhabiditis Elegans } \\
\hline \multirow{5}{*}{ Carbohydrate Metabolism } & Glycolysis \\
Gluconeogenesis \\
Metabolism of Galactose \\
Metabolism of Fructose and Mannose \\
Glycosylated pathway \\
Cycle of citric acid (TCA)
\end{tabular}

Table 2: Common metabolic pathways between mammals and $C$. elegans.

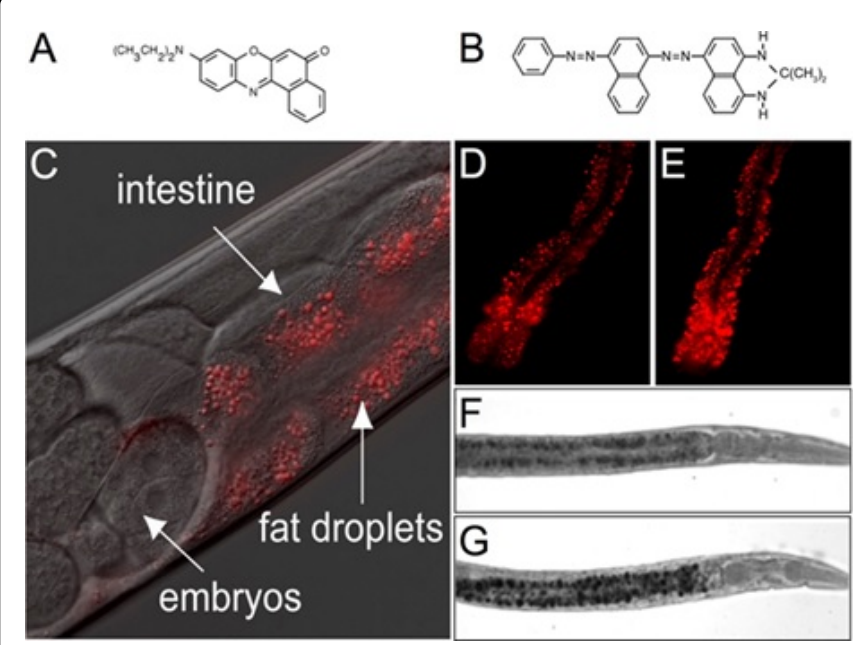

Figure 3: Visualization of intestinal lipid droplets in transparent bodies of $C$. elegans. (A-B) Chemical structures of Nile Red (A) and Sudan Black (B). (C-E) Nile Red staining in wild-type N2 animals (C, D) and tub-1(nr2004) mutants (E). In panels D and E, the head of the animal is toward the bottom of the panel. (F-G) Sudan Black staining in wild-type N2 animals (F) and TGF- $\beta$ receptor daf- 1 (m40) mutants. The head of the animal is to the right [30].

The energetic balance of the body is maintained by an extremely complex network of signaling pathways that operate in many body tissues, especially adipose and hepatic. This complex network is used to mediate different aspects of energy balance, including nutrient absorption, energy storage and modification of food behavior [38]. The compromise of some of these functions entails an imbalance that will lead to obesity. The health consequences are significant, since overweight is correlated with a wide range of pathological conditions such as cardiovascular disease, type II diabetes and various types of neoplasms $[20,39]$.

A number of approaches have already been described for the treatment of obesity, pharmaceuticals based on natural and synthetic products, physical exercises, and the chemical and nutritional properties of certain foods have now been considered. Such incessant pursuit of new approaches is due to the great need, as in recent years has seen a surprising increase in the prevalence of obesity in many countries. Concerned about transforming excess weight into a controllable disease, the need arose to evaluate potential foods that regulate an energy homeostasis and that facilitate the treatment of metabolic disorders. Many of these compounds have already been evaluated, however, they are not reproducible for comparison between humans and animal models due to the body's sophisticated energy regulatory network [40].

The common models for the study of metabolic pathways are mainly rodents, but in recent years, a new model has been deepened. $C$. elegans has been successfully reported as an animal model in research related to the characterization of metabolic pathways and storage and release of lipids [41-43]. It maintains in its cuticle and in its intestine a range of biosynthetic and catalytic enzymes, as well as reserves of lipids within its hypodermis and intestinal cells [1,42]. Using this small animal model, more than 300 genes were proven to cause a reduction in body fat when inactivated, as well as another 100 genes that when inactivated increased or stored fat $[33,44]$. It was then proposed that the use of this small worm could be beneficial because of the sharing of innumerable genes with men. Some studies have already shown that the nematode has conserved a large part of the energy homeostasis genes of humans [45].

C. elegans offers a possibility of in vivo identification of compounds that modulate fat storage due to their reduced size and short life cycle. Several foods and food components have already been characterized by reducing fat accumulation of $C$. elegans. It has been reported previously that some legumes such as red, black and marine beans act on longevity and as fat reducers [46]. As well as the use of legumes, it has been shown that oats, a nutritionally rich cereal, can also prolong life and reduce fat [47]. It provides antioxidant, anti-inflammatory and anti-angiogenic properties, and its consumption introduces a lowcalorie intervention through caloric dilution, as well as lowering lowdensity lipoprotein cholesterol, reducing body fat and risk factors for coronary disease [48-53].

Starch in its fermented resistant resistant form and short chain fatty acids could also play a significant role in reducing fat deposition in mammals as they act to inhibit intestinal deposition in C. elegans [54].

A variety of fruits like apple, pear, avocado, lemon, papaya, pineapple, when consumed in certain amounts act satisfactorily in reducing lipids. However, the momentary focus is on a lowconsumption fruit, known as Cranberry, whose properties can effectively reduce fat levels. It plays an important role in the inhibition of lipid storage in $C$. elegans through potentiation in the performance of SBP-1 and NHR-49 (nuclear hormone receptor) [55]. The NHR acts as a metabolic sensor and regulates the energy balance [56]. In the worm, this sensor resembles that of mammals, and regulates beta oxidation and expression of other genes that respond to diet. Low interaction with this sensor results in a high accumulation of fat and a decrease in mitochondrial beta oxidation [57]. SBP-1 is a crucial regulator of fatty acid synthesis and lipid homeostasis of this organism. 
By increasing the inhibition of such a regulator, $C$. elegans shows a reduction in fat content, a high content of saturated fatty acids, as well as reduced growth and reduced expression of lipogenic genes $[38,33,58,28,59]$. Another compound that is abundant in citrus fruits like orange and lemon, hesperidin, reduced fat accumulation, affecting several pathways of metabolism in C. elegans, such as fat-6 e fat-7 [60].

\section{Conclusion}

Given the difficulty in using complex animal models of mammals such as rats and mice, $C$. elegans emerged as a promising model for the study of factors that correlate with obesity and lipid metabolism. It was already known to the scientific community that food has a major contribution to the regulation of homeostasis of body energy, however, a model that resembled humans was necessary to continue the advances in the area. The application of $C$. elegans, a short-lived worm with about $65 \%$ of genes similar to humans, has opened up a new range of possibilities for research aimed at developing approaches to obesity.

\section{Competing Interests}

None of the authors has any competing interests.

All authors contributed equally to this work.

\section{References}

1. Zheng J, Greenway FL (2012) Caenorhabditis elegans as a model for obesity research. Int J Obes 36: 186-194.

2. Ogden CL, Carroll MD, Curtin LR, McDowell MA, Tabak CJ, et al. (2006) Prevalence of Overweight and Obesity in the United States, 1999-2004. JAMA 295: 1549.

3. Ayer J, Charakida M, Deanfield JE, Celermajer DS (2015) Lifetime risk childhood obesity and cardiovascular risk. Eur Heart J 36: 1371-1376.

4. Rosengren A, Aberg M, Robertson J, Waern M, Schaufelberger M, et al. (2016) Body weight in adolescence and long-term risk of early heart failure in adulthood among men in Sweden. Eur Heart J ehw221.

5. Lüscher TF (2016) Updates on prevention: obesity, ezetimibe, PCSK9, and HIV infection. Eur Heart J 37: 3545-3548.

6. Golay A, Ybarra J (2005) Link between obesity and type 2 diabetes. Best Pract. Res Clin Endocrinol Metab 19: 649-663.

7. Verma S, Hussain ME (2017) Obesity and diabetes: An update. Diabetes Metab. Syndr Clin Res Rev 11: 73-79.

8. Wolf AM, Colditz GA (1998) Current estimates of the economic cost of obesity in the United States. Obes Res 6: 97-106.

9. Hogan P, Dall T, Nikolov P, American Diabetes Association (2003) Economic costs of diabetes in the US in 2002. Diabetes Care 26: 917-32.

10. Park HEH, Jung Y, Lee SJV (2017) Survival assays using Caenorhabditis elegans. Mol Cells 40: 90-99.

11. Corsi AK, Wightman B, Chalfie MA (2015) Transparent Window into Biology: A Primer on Caenorhabditis elegans. Genetics 200: 387-407.

12. Barrière A, Félix MA (2005) High Local Genetic Diversity and Low Outcrossing Rate in Caenorhabditis elegans Natural Populations. Curr Biol 15: 1176-1184.

13. Stiernagle T (2006) Maintenance of C. elegans. WormBook.

14. Srinivasan S (2015) Regulation of body fat in Caenorhabditis elegans. Annu Rev Physiol 77: 161-78.

15. Feinberg EH, Vanhoven MK, Bendesky A, Wang G, Fetter RD, et al. (2008) GFP Reconstitution Across Synaptic Partners (GRASP) Defines Cell Contacts and Synapses in Living Nervous Systems. Neuron 57: 353-363.

16. Baumeister R, Ge L (2002) The worm in us - Caenorhabditis elegans as a model of human disease. Trends Biotechnol 20: 147-148.
17. C. elegans Sequencing Consortium (1998) Genome sequence of the nematode C. elegans: a platform for investigating biology. Science 282: 2012-2018.

18. Kaletta T, Hengartner MO (2006) Finding function in novel targets: C. elegans as a model organism. Nat Rev Drug Discov 5: 387-399.

19. Shen P, Yue Y, Park YA (2016) Living Model for Obesity and Aging Research: Caenorhabditis elegans. Crit Rev Food Sci Nutr.

20. Jones KT, Ashrafi K (2009) Caenorhabditis elegans as an emerging model for studying the basic biology of obesity. Dis Model Mech 2: 224 .

21. Hashmi S, Wang Y, Parhar RS, Collison KS, Conca W, et al. (2013) A C. elegans model to study human metabolic regulation. Nutr Metab (Lond) 10: 31

22. Mullaney BC, Ashrafi KC (2009) elegans fat storage and metabolic regulation. Biochim Biophys Acta 1791: 474-478.

23. Barros AG, de A, Liu J, Lemieux GA, Mullaney BC, et al. (2012) Analyses of C. elegans fat metabolic pathways. Methods Cell Biol 107: 383-407.

24. Watts JL, Browse J (2002) Genetic dissection of polyunsaturated fatty acid synthesis in Caenorhabditis elegans. Proc Natl Acad Sci 99: 5854-5859.

25. Satouchi K, Hirano K, Sakaguchi M, Takehara H, Matsuura F (1993) Phospholipids from the free-living nematodeCaenorhabditis elegans. Lipids 28: 837-840.

26. Holt SJ, Riddle DL (2003) SAGE surveys C. elegans carbohydrate metabolism: evidence for an anaerobic shift in the long-lived dauer larva. Mech Ageing Dev 124: 779-800.

27. Wang J, Kim SK (2003) Global analysis of dauer gene expression in Caenorhabditis elegans. Development 130: 1621-1634.

28. McKay RM, McKay JP, Avery L, Graff JM (2003) C elegans: a model for exploring the genetics of fat storage. Dev Cell 4: 131-142.

29. Van Gilst MR, Hadjivassiliou H, Jolly A, Yamamoto KR (2005) Nuclear Hormone Receptor NHR-49 Controls Fat Consumption and Fatty Acid Composition in C. elegans. PLoS Biol 3: e53.

30. Ashrafi K (2007) Obesity and the regulation of fat metabolism. WormBook 9:1-20.

31. Brock TJ, Browse J, Watts JL (2007) Fatty Acid Desaturation and the Regulation of Adiposity in Caenorhabditis elegans. Genetics 176: 865-875.

32. Hellerer T, Axang C, Brackmann C, Hillertz P, Pilon M, et al. (2007) Monitoring of lipid storage in Caenorhabditis elegans using coherent anti-Stokes Raman scattering (CARS) microscopy. Proc Natl Acad Sci 104: 14658-14663.

33. Ashrafi K, Chang FY, Watts JL, Fraser AG, Kamath RS, et al. (2003) Genome-wide RNAi analysis of Caenorhabditis elegans fat regulatory genes. Nature 421: 268-272.

34. Yen K, Le TT, Bansal A, Narasimhan SD, Cheng JX, et al. (2010) A Comparative Study of Fat Storage Quantitation in Nematode Caenorhabditis elegans Using Label and Label-Free Methods. PLoS One 5: e12810.

35. Hirsch D, Stahl A, Lodish HF (1998) A family of fatty acid transporters conserved from mycobacterium to man. Proc Natl Acad Sci U S A 95: 8625-8629.

36. Kimura KD, Tissenbaum HA, Liu Y, Ruvkun G (1997) daf-2, an insulin receptor-like gene that regulates longevity and diapause in Caenorhabditis elegans. Science 277: 942-946.

37. Kurzchalia TV, Ward S (2003) Why do worms need cholesterol? Nat. Cell Biol 5: 684-688.

38. Shen P, Yue Y, Park YA (2016) Living Model for Obesity and Aging Research: Caenorhabditis elegans. Crit Rev Food Sci Nutr.

39. Kopelman PG (2000) Obesity as a medical problem. Nature 404: 635-643.

40. Knight ZA, Shokat KM (2007) Chemical Genetics: Where Genetics and Pharmacology Meet. Cell 128: 425-430.

41. Hyun M, Davis K, Lee I, Kim J, Dumur C, et al. (2016) Fat Metabolism Regulates Satiety Behavior in C. elegans. Sci Rep 6: 24841.

42. Lynn DA, Dalton HM, Sowa JN, Wang MC, Soukas AA, et al. (2015) Omega- 3 and -6 fatty acids allocate somatic and germline lipids to ensure 
Citation: Taufner GH, Costa DS, Zanardo TEC, Destefani AC (2017) Advances in the Use of Caenorhabditis Choose in the Nutritional Study of Obesity. J Diabetes Metab 8: 735. doi:10.4172/2155-6156.1000735

Page 5 of 5

fitness during nutrient and oxidative stress in Caenorhabditis elegans. Proc Natl Acad Sci U S A 112: 15378-15383.

43. Chughtai AA, Kassak F, Kostrouchova M, Novotny JP, Krause MW, et al. (2015) Perilipin-related protein regulates lipid metabolism in C. elegans. PeerJ 3: e1213.

44. Zhang Y, Zou X, Ding Y, Wang H, Wu X, et al. (2013) Comparative genomics and functional study of lipid metabolic genes in Caenorhabditis elegans. BMC Genomics 14: 164.

45. Lemieux GA, Liu J, Mayer N, Bainton RJ, Ashrafi K, et al. (2011) A whole-organism screen identifies new regulators of fat storage. Nat Chem Biol 7: 206-213.

46. Finley JW, Sandlin C, Holliday DL, Keenan MJ, Prinyawiwatkul W, et al. (2013) Legumes reduced intestinal fat deposition in the Caenorhabditis elegans model system. J Funct Foods 5: 1487-1493.

47. Gao C, Gao Z, Greenway FL, Burton JH, Johnson WD, et al. (2015) Oat consumption reduced intestinal fat deposition and improved health span in Caenorhabditis elegans model. Nutr Res 35: 834-43.

48. Meydani M (2009). Potential health benefits of avenanthramides of oats. Nutr Rev 67: 731-735

49. Chu YF, Wise ML, Gulvady AA, Chang T, Kendra DF, et al. (2013) In vitro antioxidant capacity and anti-inflammatory activity of seven common oats. Food Chem 139: 426-431.

50. Greenway F, O'Neil CE, Stewart L, Rood J, Keenan M, et al. (2007) Fourteen Weeks of Treatment with Viscofiber ${ }^{\otimes}$ Increased Fasting Levels of Glucagon-Like Peptide-1 and Peptide-YY. J Med Food 10: 720-724.

51. Davy BM, Davy KP, Ho RC, Beske SD, Davrath LR, et al. (2002) Highfiber oat cereal compared with wheat cereal consumption favorably alters LDL-cholesterol subclass and particle numbers in middle-aged and older men. Am J Clin Nutr 76: 351-358.
52. Weickert MO, Möhlig M, Schöfl C, Arafat AM, Otto B, et al. (2006) Cereal fiber improves whole-body insulin sensitivity in overweight and obese women. Diabetes Care 29: 775-780.

53. Chang HC, Huang CN, Yeh DM, Wang SJ, Peng CH, et al. (2013) Plant Foods Hum Nutr 68: 18-23.

54. Zheng J, Enright F, Keenan M, Finley J, Zhou J, et al. (2010) Resistant Starch, Fermented Resistant Starch, and Short-Chain Fatty Acids Reduce Intestinal Fat Deposition in Caenorhabditis elegans. J Agric Food Chem 58: 4744-4748.

55. Sun Q, Yue Y, Shen P, Yang JJ, Park Y (2016) Cranberry Product Decreases Fat Accumulation in Caenorhabditis elegans. J Med Food 19: 427-433.

56. Chawla A, Repa JJ, Evans RM, Mangelsdorf DJ (2001) Nuclear Receptors and Lipid Physiology: Opening the X-Files. Science 294: 1866-1870.

57. Van Gilst MR, Hadjivassiliou H, Yamamoto KR (2005) From The Cover: A Caenorhabditis elegans nutrient response system partially dependent on nuclear receptor NHR-49. Proc Natl Acad Sci 102: 13496-13501.

58. Eberlé D, Hegarty B, Bossard P, Ferré P, Foufelle F (2004) SREBP transcription factors: master regulators of lipid homeostasis. Biochimie 86: 839-848.

59. Yang F, Vought BW, Satterlee JS, Walker AK, Jim Sun ZY, et al. (2006) An ARC/Mediator subunit required for SREBP control of cholesterol and lipid homeostasis. Nature 442: 700-704.

60. Peng $\mathrm{H}$, Wei $\mathrm{Z}$, Luo $\mathrm{H}$, Yang $\mathrm{Y}$, Wu Z, et al. (2016) Inhibition of Fat Accumulation by Hesperidin in Caenorhabditis elegans. J Agric Food Chem 64: 5207-5214. 